\title{
GEODESIGN INFORMATION MANAGEMENT AND PARAMETRIC MODELING OF TERRITORIAL OCCUPATION: NEW PARADIGMS AND CHALLENGES IN TERRITORIAL REPRESENTATION
}

\author{
S.A.Santana, Moura, ACM ${ }^{\mathrm{a}}$ \\ ${ }^{a}$ School of Architecture and Urbanism, Federal University of Minas gerais, Brazil. \\ shesantana@hotmail.com \\ anaclara@ufmg.br
}

KEY WORDS: Geoprocessing, 3D Modeling, Geodesign, Urban Planning

\begin{abstract}
:
This paper intends to be a brief contextualization about the state-of-the-art on the use of Geoprocessing on urban planning in order to present new paradigms and challenges on the use of geotecnologies focused on cities' management. Such state-of-the-art of space production justifies the current studies on geoprocessing towards the developing of tools, techniques, and methodologies which can serve the necessities of the creation of interpretative pictures of urban landscapes that may ease the dialogue among technicians, administrative workers, and the community. In this sense, this paper will show new trends, paradigms and challenges in the threedimensional models for cities representation.
\end{abstract}

\section{INTRODUTION}

\subsection{Introdution}

The space production process, ruled by the reproduction of the society, is currently making new contradictions evoked by capitalism's extension, which puts us in front of the necessity of deepen on the debate regarding the contradictions between the public and the private space; space of consumption and consumption of space; relative abundance and new rarities; fragmentation $\mathrm{x}$ globalization of the space; and instruments of urban reform. Therefore, the contradiction between the process of the space's social production and its private appropriation is on the basis of the understanding of today's spatial reproduction.

This paper wants to build a brief contextualization about the urban space's production considering the social functions of the city and the necessities on contemporary urban reforms as the trigger of recent studies on geoprocessing towards the development of tools, techniques, and methodologies which would serve the needs on the creation of interpretative pictures of urban landscapes. One is to understand that the contemporary reforms are structured from two possible thoughts. The first one is moved by the entrepreneurship supported by actions of public-private interests which aim the city's economic growth and competitiveness. They are punctual transformations through speculative constructions on the territory. The second thought, a much slower process, is based on the relative changes on the role and actions of the urban regulations. Here, the actions on the landscape production are the public power's responsibility and they consider legal instruments with standards with a wide range of planning levels and urban management.

In this sense, one of the pillars of this paper is the series of geoprocessing techniques which raise a multiple look on the territory and it allows not only the urban planning, but the management, besides allowing the scenario simulation and a wide and interactive dissemination of the knowledge acquired about the reality. This paper will show state-of-the-art of geoprocessing on urban planning, the models and modelings for urban environment so that we may present new concepts, challenges, paradigms, techniques, and methodologies for urban planning and management, specially for the Brazilian reality.

The Geoprocessing community is going under a phase of preoccupation about the transmission of the georeferenced information through systems which allow the understanding by laypeople. Internet's and multimedia expansion came as a help on the consolidation of the importance of tridimensional models on this process of minimization of the difficulties on the decodification of cartographic communication. It is on this reality that Urbanism begins to tighten its relationship with geotechnologies. The tridimensional models are becoming stronger and a more important support system to the planning through the communication of the landscape potential approved by the regulations made by planners and technicians responsables by the approval of urban actions. In this sense, it is evident the demand for a set of techniques and enabling technologies for planning built environments in an integrated process, including project conceptualization, analysis, design specification, stakeholder participation and collaboration, design creation, simulation, and evaluation. So, the geodesing brings a a planning approach that grounds design methods and practices in temporal and spatial knowledge of human and natural geographic contexts. It is from the convergence of the geographic information systems and the building information modeling that we present a study on a practical response to the concepts which bear with them new challenges and paradigms on the representation of the urban space, the Parametric Modeling of Territorial Occupation (MPOT).

\section{GEOPROCESSING ON THE URBAN PLANNING}

The decisions on urban planning collide with political, operational, and structural questions which are developed with 
so many variables that the choices are difficult to be defined without a systematic study. To know the territory, stage of the changes on the territorial dynamics, is the most precise way of decision making, aware about the ways to go through in order to reach the defined aims on the planning. In this sense, one may defend that the best way to analyze and manage the information for a good municipal management is through the application of geoprocessing techniques. Such statement is backed because they favor the information integration, the composition of the variables in a systematic way, the proposition of possible scenarios, and the picture construction of the reality as per different looks and values.

Regarding the importance of making a previous picture, or several pictures that show the urban complexity before the process on its ordinance is started, Niccola (1991, p. 20) asserts: "To read the territory before projecting, before planning". This thought is completed by Van Der Berg and Van Der Meer (1991, p. 41) when they say that "it is the time of the programmed planning. There should be space for flexibility and creativity".

The information that is organized, correct, and easily available is a strategic and essential resource to an accurate and timesensitive decision making. Moura (2010) asserts that Geoprocessing is an important management tool, for it is a set of technologies to the information processing whose geographical localization is an indispensable, intrinsic characteristic to its analysis. The use of geoprocessing techniques helps the analysis production in the most recent trends, most of all when the aim is the production of data analysis and the mapping of the information acquired. This way, the GIS (Geographic Information System) is able not only of storing, but also of managing, crossing, analyzing a range of data proceeded from several sources and with different formats. This makes the tool ideal to represent the urban environment and its high complexity. It is interesting to say that the GIS produces a multiple look towards the territory and allows not only to plan, but also to manage the urban environment. Besides, it allows also the scenario simulation and the wide and interactive dissemination of the acquired knowledge about the reality.

With Internet and its power, the GISs were adapted to become available to the big public through WebGIS. WebGIS brought with it the need to develop languages, data access ways, and information construction which were highly communicative and encouraged the use by the non-specialist public.

The fast and ever-growing information diffusion allowed by the Internet brought with it the necessity of verifying the quality, the origin, and the access to the information and to the data collection. The regulations didn't take long to be written and, while Europe came up with INSPIRE, Brazil had its decree 6666, from November 27th, 2008, by the Ministry of Planning, which defines rules and parameters for the structure at the National Infrastructure of Spacial Data (INDE, as in its Portuguese abbreviation). INDE's intentions need to be duplicated to the several management and spacial information diffusion instances, mainly state and local ones.

Hence, the recent scenario is that of the application of geoprocessing techniques through actions of interoperability, system integration, and the integration of different users sections. The urbanists have always had the preoccupation of anticipate their intentions' results through tools of graphic expression - firstly by drawings and currently through augmented reality. A new way of digital representation of objects called BIM (Building Information Modeling) was born at the graphic representation of project areas, among which one can find Architecture. According to Moura (2012), BIM's logic is to compose in order to decompose, which is the opposite of GIS's logic: decompose in information patterns and alphanumeric tables and then compose into a synthesis process or an integration of information. At BIM, the object is represented on four dimensions and, from the existence of the object as a whole, it may be decomposed into its different patterns, whichever they may be: plans, sections, facades, data bank, among others.

Because the object is presented as a system, any alteration on one of its characteristics results on alterations and updates on the visualizations at the different information representation levels. However, the focus of these tools remains on individual new building construction within representations containing almost no information about their geographic context. Conversely, the representation of built forms within geographic information systems (GIS) remains overlay simplistic, usually consisting of $2 \mathrm{~d}$ footprints. This makes it difficult to conduct neighborhood, city or regional scale assessments that take into account important characteristics of design proposals.

It is based on the interest of not only model interpretative pictures, but also to generate reality's simulations that the BIMs gained so much power in the context of the technologies of digital representation and are heading towards being incorporated to the geoprocessing club through the symbiosis of BIM and GIS.

BIM is still very recent and does not have GIS's maturity, but the convergence and the integration of both models, concepts, and systems that will bring to the geoprocessing arena a new way of thinking: GIM, Geodesign Information Modeling.

This new paradigm, called Geodesign, is a design and planning method which tightly couples the creation of a design proposal with impact simulations informed by geographic context. In an ideal case, a planner or designer receives real-time guidance on performance at every phase of design from early site visit or conceptual sketch to final detail. The use of contextual geographic information means that design performance can be evaluated relative to local conditions, and that evaluation can and should consider off-site impacts. The focus is on supporting "human in the loop" design, providing continuous feedback on multiple aspects of performance and improving designs-inprogress rather than on post-hoc evaluation. The Geodesign information models are, therefore, systems that allows sketing interface within GIS to connect this directly to geoprocessing models so as to support a novel mechanism for rapidly generating spatial features with attributes, a tightly coupling design and assessment of sketch in the built georreferenced landscape and a design-time feedback. The first two concepts oriented the softwars Placeway's CommunityViz and Criterion Planner's INDEX.

These new support systems to planning, henceforward called GIM, are based as a support to projects that are no longer restrained only to the territory's design, but they respond to the intentions of urban landscapes' simulations. The GIM may even become more innovative if the data modeling respond to the proposals of the creation of parametric scenarios of the composition of the territory's occupation - which Moura (op cit) has been calling "Parametric Modeling of Territorial Occupation".

The new way, GIM together with Parametri Modeling of Territorial Occupation, comprehend an environment full of opportunities to the geotechnologies to analyze, simulate, propose, project detailing, and communication with different users. To do so, there is the need for integrated systems, interpretative pictures construction and modeling, reality simulators, investment in visualization and better involvement with the community, interoperability between systems. 
The conditions we have right now allow the urbanist to simulate, on augmented reality, the landscapes which are the result of its zone propositions, occupation models, and urban parameters table. This - widely used as a work tool by the urbanist - will allow the bridge between the languages spoken by the technicians, the administration, and the community, for, as the City Planning and its pieces are approved, the users will have a virtual representation of the proposed parameter's meaning. Everyone can, then, decide, in a democratic way and with the support of the best communication forms, about the projects which can result on the expected with the landscape and in harmony with the cultural values of the society related to the territory.

Giacomelli, in Campagna (2006, p. 187), asserts that the complexity of these models and the variety and volume of the information need to be studied regarding the processing and post-processing environment related not only to GIS technology, but also to the host tool which will build such interface of a system of scientific visualization, image processing, and data management. This support system is a result of the composition of several elements and model ways that make the systems strong and heavy.

In this sense, CityEngine is presented as a 3D modeling software specialized on models of urban environment. CityEngine was developed at the ETH Zurich, by author Pascal Mueller, co-founder and CEO of Inc Processual. While researching his $\mathrm{PhD}$ at ETH Computer Vision Lab, Mueller invented a big quantity of innovative techniques on procedural modeling on 3D content for architecture, which were compiled and made today's CityEngine software.

CityEngine was bought by ESRI, company owner the main commercial GIS software in the world (ArcGis), and because of such change the software started incorporating the data's georreferenced specialization logic, besides the possibilities of normative standards definitions on the zoning of the urban soil, becoming interesting for a work in the direction of the MPOT.

This paper will use CityEnging as the default GIM system with parametric model of territorial occupation in the concepts presented before, from the programming of algorithms of the established parameters by Belo Horizonte's City Planning for the allowed landscape evaluation allowed by the urban normative. In this sense, it will be possible to give to public administrators a system able to direct the definition of areas with a transformation potential and the preferred areas for urban densification.

\section{METODOLOGY}

This paper's methodology begins with the research on new geoprocessing values and concepts; reading and reflection about the state-of-the-art on the concepts of the regulation norms of the urban landscapes transformations and in the choice of the more appropriate tools regarding the necessities of the planning and the landscape management. One should always have in mind the specific interests of finding a support system to the planning that comprehends the new concepts on GIM and MPOT.

The first step was to evaluate whether the software chosen, CityEngine, was really open to the inclusion of the parameters defined by the Brazilian urban norms. Here, during the construction of the rules, it was necessary to tabulate the information on Belo Horizonte's urban parameters in order to verify which are the permissions and restrictions on each zoning standard.

From Belo Horizonte's city planning, several data was extracted, such as the use coefficient, territory quota, occupation rate, maximum height at the division, separation, among others.

Once the parameters for each zoning area were verified, it was necessary develop a logic to support the parametric algorithm to be inserted in the system. It was decided that at a first moment, when there were tests on the rules creation, the parameters to be used were use coefficient, occupation rate, maximum height at the division, and separations. Such parameters were the ones selected because they were the most complex on the algorithm's input.

A test area was used to verify whether the rules were able to model the city and a tridimensional interpretative picture of how the city would be if the maximum allowed were built on each plot, as specified on the urban parameters defined by the urban planning. (Figure 1)

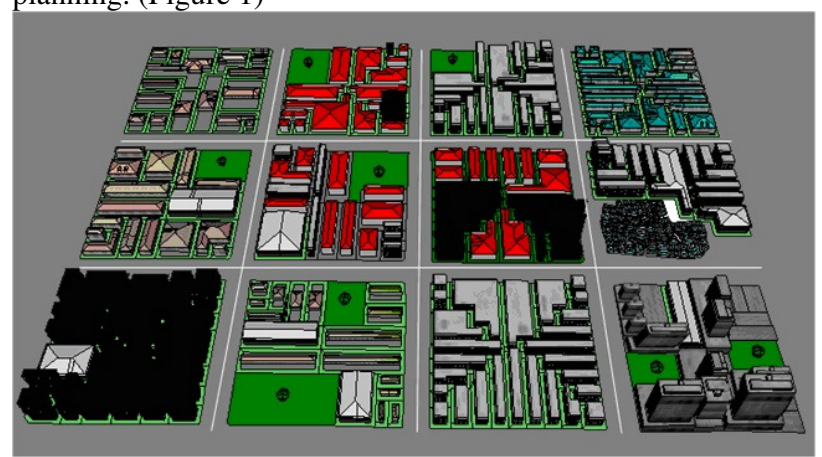

Figure 1 - Test Area

After the construction of this model, Belo Horizonte's database was used to build a model of the real city, as Figure 2 shows.

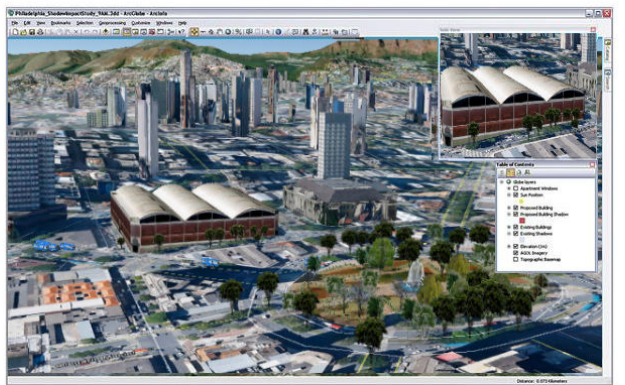

Figure 2 - Example of real model of Belo Horizonte

It is important to say that it was used a collaborative tridimensional mapping through Google's sketch. This process was important because it was possible texture the buildings following real information. At this point, more than $50 \%$ of the city was mapped.

With the modeling of the real city and the one of the city using the urban parameters, it was possible to compare the places where there is a building stock, i.e., places where people could build more following the city planning, but they decided to build lower buildings. (Figure 3) 


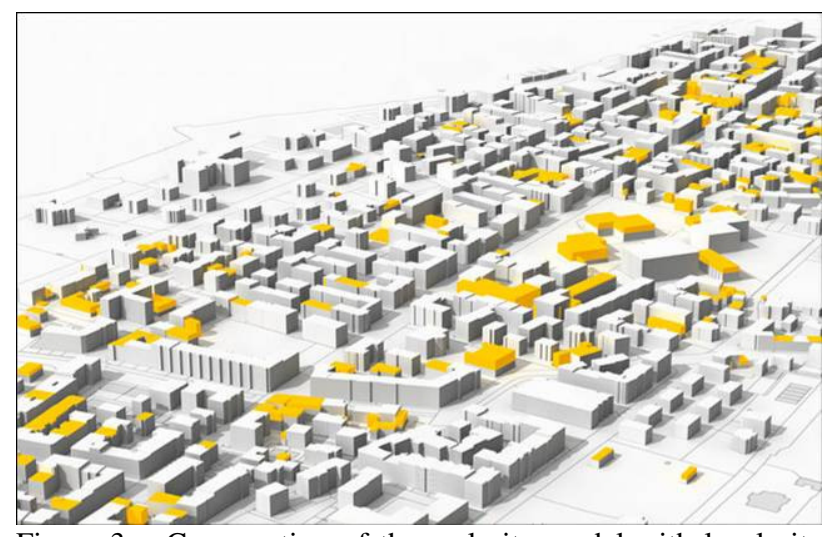

Figure 3 - Comparation of the real city model with legal city model.

The definition of such building stocks was the first step to verify the places susceptible of urban growth.

Later, both models were published on the web so that the data was available for the community.

\section{DISCUSSION}

We are facing new paradigms and challenges on the territorial representation, specially the urban one. This paper indicates that we are in the right path towards the elaboration of a support system to the planning that will show the conformation of the urban proposals by the technicians so that a more efficient and participative planning is possible. The landscape preview to be constructed will allow the evaluation whether we are leading the city towards an urban expansion aligned with the logic of maintenance of the city's social function.

Both models were published on the web within the WebScene concept. The motivation was based on the citizens' participation on the process of building approvals in the city. The visualization of the impacts in the city before they happen allowed opening in the discussion about the insertion of the solar envelope models as a restrictive urban parameter towards the building potential.

The next steps will be: the preparation of a model of the entire city of Belo Horizonte following the urban norms, the preparation of a model of the city of Belo Horizonte as its real state, the comparison between both models in order to indentify areas with building stocks and possibilities of landscape renovation to help on the definitions of probable areas to urban densification and the receipt of coefficients which are a result of operations on urban regulations existing in the country.

It is important to emphasize that this is a very innovative work, and there were several difficulties on the definition of the rules' logic. Also, there were difficulties on the compilation of such information on the parametric database comprehended by the software. The results showed enlighten a great evolution within the scenario modeling, for it had never been developed in Brazil.

\section{REFERENCES}

Giacomelli, A. Integration of GIS and Simulation Models, p.181 - 192 In: Campagna, M. GIS for sustainable development. CRC Press, 2006 - ISBN 0-8493-3051-3 (alk. paper), 535p.

NICCOLA, C. (1991) Dialettica di modelli e fattori d'incertezza nelo studio dele aree metropolitane. In.: Bolognafiere - SAIE. Il projeto metropolitano: la città Europea, Bologna: Fiere di Bologna. p. 20.

Moura, Ana Clara M. (2012 b). Learning topics in urban planning at UFMG: geoprocessing to support analysis, planning and proposal of the urban landscape at neighborhood scale. 5th International Seminar on Environmental Planning and Management - Urban Responses for Climate Change - Brasilia, Brazil - October 18 - 20, 2012. 15 p.

MOURA, Ana Clara M., MOURA, Carlos Alberto, SANTANA, Sheyla Aguilar, LANNA, Lucas S., AZEVEDO, Úrsula Caroline, LOURENÇO, Paula M. Geoprocessamento nos diagnósticos e prognósticos de áreas de interesse especial ao na área de influência das linhas de transmissão da CEMIG - estudo de caso da RMBH. Anais do XXIV Congresso Brasileiro de Cartografia , Aracaju-SE, 2010.

Van der Berg, L. Van der Meer, J. (1991). Politica e gestione urbana, il caso Rotterdam. In.: Bolognafiere - SAIE. Il projeto metropolitano: la città Europea, Bologna: Fiere di Bologna. p. 41. 